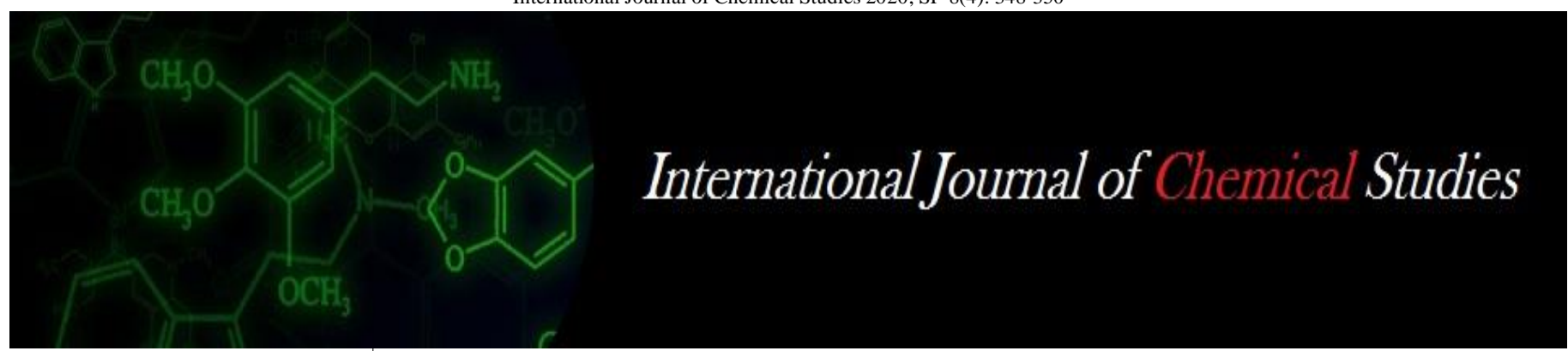

P-ISSN: 2349-8528

E-ISSN: 2321-4902

www.chemijournal.com

IJCS 2020; SP-8(4): 348-350

(C) 2020 IJCS

Received: 20-05-2020

Accepted: 22-06-2020

\section{PH Vihariya}

Ph.D., Scholar, Department of Extension Education, NMCA, NAU, Navsari, Gujarat, India

MR Patel

Assistant Extension

Educationist, Sardar Smruti

Kendra, DOEE, AAU, Anand,

Gujarat, India

\section{NB Thakur}

Ph.D., Scholar, Department of Extension Education, BACA, AAU, Anand, Gujarat, India

Corresponding Author:

PH Vihariya

Ph.D., Scholar, Department of

Extension Education, NMCA,

NAU, Navsari, Gujarat, India

\section{Adoption of recommended environmental protection measures among vegetable growers to combat hazardous effect caused through pesticide residues in vegetables}

\author{
PH Vihariya, MR Patel and NB Thakur
}

DOI: https://doi.org/10.22271/chemi.2020.v8.i4f.10091

\begin{abstract}
The present study was conducted on a random sample of 120 vegetable growers selected from the 12 random villages of Anand, Borsad and Petlad Taluka of Gujarat state.The methodological procedure consisted of dependent and independent variables. The data were collected through personal interview using structured interview schedule. The collected data were classified, tabulated, analyzed and interpreted in order to make the findings meaningful. The statistical measures such as percentage and frequency were used in the study. Data of the research study stated that slightly more than one half (51.66 per cent) of the vegetable growers had low level of adoption about recommended environmental protection measures, followed by 35.00 per cent, 7.50 per cent and 5.84 per cent in medium, very low and high level of adoption category, and nobody were found in very high level of adoption category, respectively. So, majority ( 86.66 per cent) of the vegetable growers were having low to medium level of adoption about recommended environmental protection measures in vegetable cultivation.
\end{abstract}

Keywords: Adoption, recommended environmental protection measures, hazardous effect, pesticide residues

\section{Introduction}

India is the one of the largest producer of vegetables, next to China and vegetables are being grown in open as well as under protected environment. The productivity of different vegetables in our country is comparatively lower than the world's average productivity because of insect -pest infestation. For better yield and quality, pesticides are repeatedly applied by farmers during the entire period of vegetable farming including the fruiting stage. Indiscriminate use of pesticides particularly at fruiting stage and non-adoption of safe waiting period leads to accumulation of pesticide residues in consumable vegetables. If farmers become more aware of the judicious use of pesticides and to adopt recommended environmental protection measures it will reduce the hazards related to pesticide residues. It can only be achieved when the farmers will get the right information about hazards caused by improper, careless, and excessive use of pesticides from the various sources of information. Keeping all the above facts in mind, the present study entitled "Adoption of recommended environmental protection measures among vegetable growers to combat hazardous effect caused through pesticide residues in vegetables".

\section{Objective}

To extent the adoption about recommended environmental protection measures among vegetable growers to combat hazardous effect caused through pesticide residues in vegetables

\section{Research methodology}

The present study was conducted among eight districts under the jurisdiction of Anand Agricultural University, Anand district was purposively selected for the study because vegetable crops grown more or less in all the talukas of the Anand district. Out of 8 Talukas of Anand district Anand, Borsad and Petlad talukas where vegetables (Brinjal, Okra and Chilli) are grown on maximum areas were selected purposively. Thereafter, four villages from each 
taluka were selected by using simple random sampling for study purpose. From 12 selected villages 120 respondents were selected by proportionate random sampling technique for study purpose. The investigator collected data by using personal interview method. The collected data were analyzed by using Frequency and Percentage.

\section{Measurement of adoption}

The adoption process is a mental process through which an individual pass from first hearing about an innovation to its final adoption. In this study the adoption is defined as "actual use of recommended plant protection measures in vegetable production by the farmers." Structure schedule was developed to collect the data/ information pertaining to extent of adoption of plant protection measures in vegetable cultivation. The schedule consists of 26 questions concerning recommended plant protection measures in vegetable production technology. Respondents were asked to answer whether they have adopted these recommended plant protection measures or not in terms of yes or no response. The correct answers were tick $(\sqrt{ })$ marked and assigned one score. The total number of ticks marked questions was the adoption score of the individual respondent about the test. Respondent's extent of adoption was determined by Adoption Index.

The respondents were classified into five categories using arbitrary method of classification as under: (1) Very low (2) Low (3) Medium (4) High and (5) Very high level of adoption which was calculated through this formula:

Total numbers of actual adopted

$\mathrm{AI}=$ protection measures by individual farmer $\mathrm{x} 100$ Total numbers of protection measures

$(\mathrm{AI}=$ Adoption Index $)$

\section{Result and discussion}

The adoption process is a mental process through which an individual pass from first hearing about an innovation to its final adoption. In this study the adoption is defined as "actual use of recommended environmental protection measures in vegetable cultivation by the farmers." The results on this aspect are presented in Table 1:

Table 1: Distribution of vegetable growers according to their level of adoption

\begin{tabular}{|c|c|c|c|}
\hline \multirow{2}{*}{ S. No. } & \multirow{2}{*}{ Adoption (Score) } & \multicolumn{2}{c|}{$(\mathrm{n}=120)$} \\
\cline { 3 - 4 } & & Fegetable growers \\
\hline 1. & Very low (up to 20 score) & 09 & 07.50 \\
\hline 2. & Low (21 to 40 score) & 62 & 51.66 \\
\hline 3. & Medium (41 to 60 score) & 42 & 35.00 \\
\hline 4. & High (61 to 80 score) & 07 & 05.84 \\
\hline 5. & Very high (81 to 100 score) & 00 & 00.00 \\
\hline \multicolumn{2}{|c|}{ Total } & 120 & 100.00 \\
\hline
\end{tabular}

The findings presented in Table 1 and Figure 1 it made clear that slightly more than one half (51.66 per cent) of the vegetable growers had low level of adoption, followed by 35.00 per cent, 7.50per cent and 5.84 per cent in medium, very low and high level of adoption category, and nobody were found in very high level of adoption category, respectively. Thus, it can be concluded that majority ( 86.66 per cent) of the vegetable growers were having low to medium level of adoption about recommended environmental protection measures in vegetable cultivation. This finding is line with Badhe (2012) ${ }^{[1]}$.

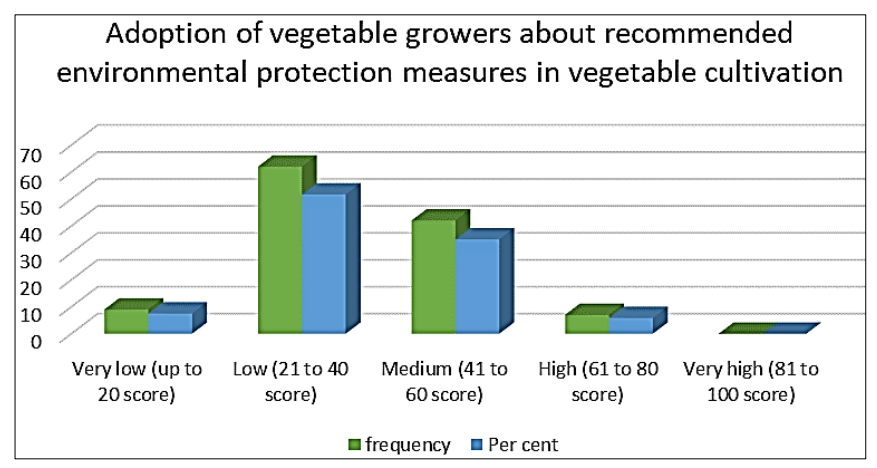

Fig 1: Distribution of vegetable growers according to their level of adoption $(n=120)$

The probable reason might be that they were not aware about the safety measures and which did not be followed by them strictly for protecting environment at the time of spraying of pesticides in the field even they did not wearing safety clothes at the time of applying pesticides in the field for taking care of their health and also they go away for better standard of living they little bit adopt recommended environmental protection measures or to get higher market price of their product they did not adopt recommended waiting period for reducing hazardous effect of pesticides residues in vegetables.

\section{Conclusion}

Majority (86.66 per cent) of the vegetable growers were having low to medium level of adoption about recommended environmental protection measures in vegetable cultivation. Thus, the outcome of this study would be helpful for creating awareness among vegetable growers about environmental hazards which can be occurred by low adoption of environmental protection measures and these will serve as a guideline to planners and extension agencies to understand the better ways and means of promoting eco-friendly measures among the group of clientele to check environmental hazards.

\section{Suggestions for further research}

This type of study should be conducted in different areas to extent the adoption of recommended environmental protection measures among vegetable growers to combat hazardous effect caused through pesticide residues in vegetables. The research should be extended to large number of farmers to draw valid conclusions. Some other characteristics of the farmers, other than those included in this study, might be affecting their adoption regarding recommended environmental protection measures in vegetables should be identified and studied. Such study should be repeated after some lapse of time on large sample size to increase its validity.

\section{References}

1. Badhe DK. Farmers Perception Regarding Environmental Risk in Use of Pesticides in Anand District of Gujarat State (Master's thesis, Anand Agricultural University, Anand), 2012.

2. Dureja P, Gupta RL. Status of pesticide of India, Pesticide research journal. 2009; 21(2):202-210.

3. Handa SK, Agnihotri NP, Kulshrestha G. Pesticides Residues: Significant Management and Analysis. Research Periodicals and Book Publishing Home, Texas, USA, 1999. 
4. Patel BD. A study on adoption of recommended chilli technology in Vadodara district (Master's thesis, Anand Agricultural University, Anand), 2005.

5. Ram K. Perception of paddy growers about environmental hazards caused through injudicious use of chemicals in paddy cultivation (Master's thesis, Anand Agricultural University, Anand), 2015. 